\title{
The role of nuclear imaging in the failing heart: myocardial blood flow, sympathetic innervation, and future applications
}

\author{
Mark J. Boogers • Kenji Fukushima • \\ Frank M. Bengel $\cdot$ Jeroen J. Bax
}

Published online: 12 October 2010

(c) The Author(s) 2010. This article is published with open access at Springerlink.com

\begin{abstract}
Heart failure represents a common disease affecting approximately 5 million patients in the United States. Several conditions play an important role in the development and progression of heart failure, including abnormalities in myocardial blood flow and sympathetic innervation. Nuclear imaging represents the only imaging modality with sufficient sensitivity to assess myocardial blood flow and sympathetic innervation of the failing heart. Although nuclear imaging with single-photon emission computed tomography (SPECT) is most commonly used for the evaluation of myocardial perfusion, positron emission tomography (PET) allows absolute quantification of myocardial blood flow beyond the assessment of relative myocardial perfusion. Both techniques can be used for evaluation of diagnosis, treatment options, and prognosis in heart failure patients. Besides myocardial blood flow, cardiac sympathetic innervation represents another important parameter in patients with heart failure. Currently, sympathetic nerve imaging with 123-iodine metaiodobenzylguanidine (123-I MIBG) is often used for the assessment of cardiac innervation. A large number of studies have shown
\end{abstract}

M. J. Boogers · J. J. Bax ( $\bowtie)$

Department of Cardiology, Leiden University Medical Center, Albinusdreef 2, 2333 ZA Leiden, The Netherlands e-mail: j.j.bax@lumc.nl

M. J. Boogers

e-mail: j.m.j.boogers@lumc.nl

M. J. Boogers

The Interuniversity Cardiology Institute of the Netherlands, Utrecht, The Netherlands

K. Fukushima - F. M. Bengel

Division of Nuclear Medicine, The Russel H. Morgan

Department of Radiology, Johns Hopkins University,

Baltimore, MD, USA that an abnormal myocardial sympathetic innervation, as assessed with 123-I MIBG imaging, is associated with increased mortality and morbidity rates in patients with heart failure. Also, cardiac 123-I MIBG imaging can be used to risk stratify patients for ventricular arrhythmias or sudden cardiac death. Furthermore, novel nuclear imaging techniques are being developed that may provide more detailed information for the detection of heart failure in an early phase as well as for monitoring the effects of new therapeutic interventions in patients with heart failure.

Keywords Nuclear imaging - Myocardial blood flow . Sympathetic innervation $\cdot$ Heart failure

\section{Heart failure}

The clinical syndrome of heart failure remains an important condition with markedly increased morbidity and mortality rates over the last several decades [1,2]. The American Heart Association Statistics and Stroke Statistics Committee have reported that the estimated life-time risk for development of heart failure is approximately $20 \%$ at the age of 40 years [2]. At present, a total number of 5,300,000 patients have been diagnosed with heart failure in the United States, representing about $2.5 \%$ of the population aged $\geq 20$ years. Moreover, heart failure represents a considerable health care issue as the number of annual hospital admissions grew dramatically by $171 \%$, from 400,000 in 1979 to $1,084,000$ in 2005 [2]. Beyond the increasing number of newly diagnosed heart failure patients and hospital admissions, heart failure accounts for a large number of cardiac deaths in the western world, with an estimated 5-year mortality rate of $54 \%$ in men and $40 \%$ in women [3]. 
Heart failure is considered a complex clinical syndrome resulting from a decreased cardiac pump capacity which lacks the ability to provide sufficient metabolic demands to peripheral tissues. The progressive loss of functional and viable cardiomyocytes and the inability of viable myocardium to contract normally play an important role in development of heart failure. In patients with heart failure, several underlying mechanisms have been identified that interact markedly in the pathophysiology of dysfunctional myocardium, including abnormalities in coronary flow, myocardial blood flow, cell metabolism, and sympathetic innervation of the myocardium.

Regardless of the underlying pathophysiologic mechanisms, various compensatory feedback systems, including the sympathetic nervous system and renin-angiotensinaldosterone system, are activated in patients with heart failure which aim to modulate the deprived cardiac pump function within a normal homeostatic range [4-7]. Although activated feedback systems act favorably in the early phase by positive inotropic, chronotropic, and dromotropic effects, they become deleterious in a chronic state as they may cause myocardial hypertrophy and fibrosis, leading to cardiac remodeling and restructuring. Accordingly, secondary endorgan damage of the myocardium may further enhance the progressive decline in cardiac function, resulting in overt clinical symptoms of heart failure.

A comprehensive evaluation of heart failure patients remains challenging these days, as it requires integrated information on heart failure etiology, pathophysiology and prognosis. At present, heart failure patients can be evaluated with the use of different non-invasive imaging techniques, including echocardiography, magnetic resonance imaging as well as nuclear imaging. Among the currently available imaging techniques, nuclear imaging represents the only imaging modality with sufficient sensitivity to provide insights into myocardial and cellular mechanisms involved in the etiology, pathophysiology and prognosis of patients with heart failure $[8,9]$. More specifically, nuclear imaging provides detailed information on several biological processes in heart failure, including myocardial blood flow and sympathetic innervation of the myocardium, which are considered important tissue characteristics of the failing heart.

Accordingly, the current review will provide an overview of the potential role of nuclear imaging techniques for tissue characterization in patients with heart failure, with particular focus on the assessment of myocardial blood flow and sympathetic innervation of the failing heart. In addition, the potential role of molecular imaging in the field of heart failure will be provided; novel techniques may help in prevention of development of heart failure and could possibly guide novel therapeutic options for heart failure.

\section{The potential of nuclear imaging in heart failure}

Myocardial perfusion imaging represents the mainstay of cardiovascular radionuclide applications for the diagnostic and prognostic workup of patients with coronary artery disease and heart failure [10]. In addition, sympathetic innervation imaging is increasingly used in patients with heart failure, predominantly for risk stratification.

At the same time, considerable improvements in nuclear imaging technology have led to an evolution of clinical nuclear imaging beyond the isolated assessment of myocardial perfusion and sympathetic innervation, toward the characterization of molecular processes at the cardiac tissue level.

Several technical advances have been introduced that contribute to the current trend toward molecular-targeted imaging in clinical cardiology. At first, the availability of high-end scanner systems with improved detection sensitivity and image resolution allow the detection of weak signals coming from tissue-specific molecular-targeted tracers. Furthermore, the availability of positron emission tomography (PET) systems has increased markedly over the recent years due to its success in oncology [9]. Moreover, an increasing number of molecular-targeted radiotracers is now being introduced which may extend the current possibilities for molecular imaging of biologic processes. Finally, it is important to note that moleculartargeted imaging is of growing interest as nuclear systems are increasingly integrated with computed tomography (CT) systems into single-photon emission computed tomography (SPECT)-CT or PET-CT hybrid imaging devices, which facilitate the localization of a molecular signal, by fusion with high-resolution morphologic images [9].

Potentially, these dedicated nuclear imaging techniques with their unique translational potential and their superior detection sensitivity can play an important role in the evaluation of patients with heart failure as they provide important information on several biological processes of the failing heart, including myocardial blood flow and sympathetic innervation of the myocardium.

\section{Myocardial blood flow in the failing heart}

Myocardial perfusion can be evaluated with the use of different nuclear imaging techniques, including SPECT and PET imaging. Myocardial perfusion SPECT represents a well-established and safe imaging modality for the evaluation of location, extent and severity of myocardial perfusion defects [11]. In clinical cardiology, 3 commercially available SPECT tracers $\left({ }^{201}\right.$ Thallium, ${ }^{99 \mathrm{~m}} \mathrm{Tc}$-tetrofosmin, and ${ }^{99 \mathrm{~m}} \mathrm{Tc}$-sestamibi) (Table 1) are most commonly used to 
Table 1 Myocardial perfusion PET/SPECT tracers

\begin{tabular}{lllll}
\hline & Half-life & Production & First-pass extraction $(\%)$ & Kinetic properties \\
\hline $\begin{array}{l}\text { SPECT tracers } \\
{ }^{201} \text { Thallium }\end{array}$ & $73 \mathrm{~h}$ & Delivery & 70 & Na/K ATPase channel \\
${ }^{99 \mathrm{~m}}$ Tc-tetrofosmin & $6 \mathrm{~h}$ & Generator/delivery & 40 & Diffusible, mitochondrial binding \\
${ }^{99 \mathrm{~m}} \mathrm{Tc}$-sestamibi & $6 \mathrm{~h}$ & Generator/delivery & 50 & Mitochondrial membrane potential \\
$P E T$ Tracers & & & & Metabolic trapping \\
${ }^{13} \mathrm{~N} \mathrm{NH}_{3}$ & $10 \mathrm{~min}$ & Cyclotron & 85 & Na/K ATPase channel \\
${ }^{82} \mathrm{Rb}^{15} \mathrm{O} \mathrm{H}_{2} \mathrm{O}$ & $76 \mathrm{~s}$ & Generator & 65 & Freely diffusible \\
${ }^{18} \mathrm{~F} \mathrm{BMS747158}$ & $122 \mathrm{~s}$ & Cyclotron & 100 & Binds to mitochondrial complex-1 \\
\hline$P E T$ P & $110 \mathrm{~min}$ & Cyclotron/Delivery & 90 &
\end{tabular}

PET positron emission tomography, SPECT single-photon emission computed tomography

evaluate the presence, extent, and reversibility of myocardial perfusion defects in patients with suspected or known coronary artery disease.

Although myocardial perfusion SPECT is still the clinical mainstay, PET imaging is being increasingly utilized in clinical cardiovascular imaging practice [9]. It has been shown that PET imaging allows accurate detection of significant coronary artery disease, which may be superior to SPECT imaging in particular subsets of patients [12]. Moreover, it is important to note that PET imaging provides information beyond the assessment of relative regional myocardial perfusion. In PET imaging, high temporal resolution and additional methodological advantages enable the absolute quantification of myocardial blood flow and flow reserve, contributing to the assessment of underlying etiology of heart failure (ischemic versus non-ischemic cardiomyopathy). Hypoperfusion of the myocardium, either due to macro-vascular flow-limiting coronary artery disease or abnormalities in coronary microcirculatory flow, will lead to distortion of fatty acid and glucose cell metabolism as well as the myocardial storage of high-energy and creatine phosphates, and as a consequence, can cause a dysfunctional contraction pattern of the myocardium. Furthermore, chronic myocardial hypoperfusion may result in irreversible loss of functional and cellular integrity, leading to cell death and fibrosis [5].

Several PET tracers are currently available for assessment of myocardial perfusion (Table 1), of which N-13 Ammonia $\left({ }^{13} \mathrm{NH}_{3}\right)$ and Rubidium-82 $\left({ }^{82} \mathrm{Rb}\right)$ are both approved for clinical use by the US Food and Drug Administration (FDA). Both ${ }^{13} \mathrm{NH}_{3}$ and ${ }^{82} \mathrm{Rb}$ can be used for absolute quantification of myocardial blood flow in addition to relative regional perfusion analysis. To evaluate myocardial blood flow, the first-pass extraction percentage of the tracer represents an important tracer characteristic, and for this reason, $\mathrm{O}-15$ water is widely considered as the most ideal flow tracer due to its first-pass extraction of $100 \%$. Furthermore, F-18-labeled compound BMS747158 $\left({ }^{18} \mathrm{~F}\right.$-BMS $)$ is considered another high potent tracer for myocardial flow imaging as it shows a first-pass extraction percentage exceeding $90 \%[13,14]$.

With the use of PET tracers, simultaneous conventional image analysis (relative regional perfusion and function) and absolute flow quantification can be performed, as illustrated schematically in Fig. 1. Dynamic imaging with multiple time frames requires a high count density and advanced data processing, which is increasingly becoming a routine feature in the novel state-of-the-art PET systems. For tracer kinetic analysis, the arterial input function and myocardial kinetics are measured from regions of interest in sequential (dynamic) images. Absolute flow quantification is achieved by employing compartmental modeling analysis to the obtained time-activity curves. At present, various tracer kinetic models have been established according to the nature of the each PET tracer $[15,16]$, and validation studies have been performed in experimental settings. Although several comparison studies have noted distinct differences between PET tracers, a good reproducibility for flow measurements has been established, which underlines the feasibility of PET imaging for assessment of myocardial blood flow [17-19].

Currently, several studies using PET imaging have demonstrated that myocardial blood flow and flow reserve are influenced by a number of factors. On the one hand, myocardial blood flow and flow reserve are strongly influenced by systemic cardiovascular hemodynamics as well as aging [20]. Aging, increasing heart rate and increasing systemic blood pressure cause an augmented baseline work of the heart, leading to a higher rest myocardial blood flow. Accordingly, the myocardial flow reserve, which is expressed as the ratio of stress to rest flow, will be reduced. Furthermore, nuclear studies have shown that myocardial blood flow and flow reserve can be influenced by conventional cardiovascular risk factors, such as smoking, dyslipidemia, and diabetes [21, 22]. Additionally, it has been postulated that therapeutic interventions and cardiovascular risk modification can influence myocardial blood flow or flow reserve of the heart [20-22]. 


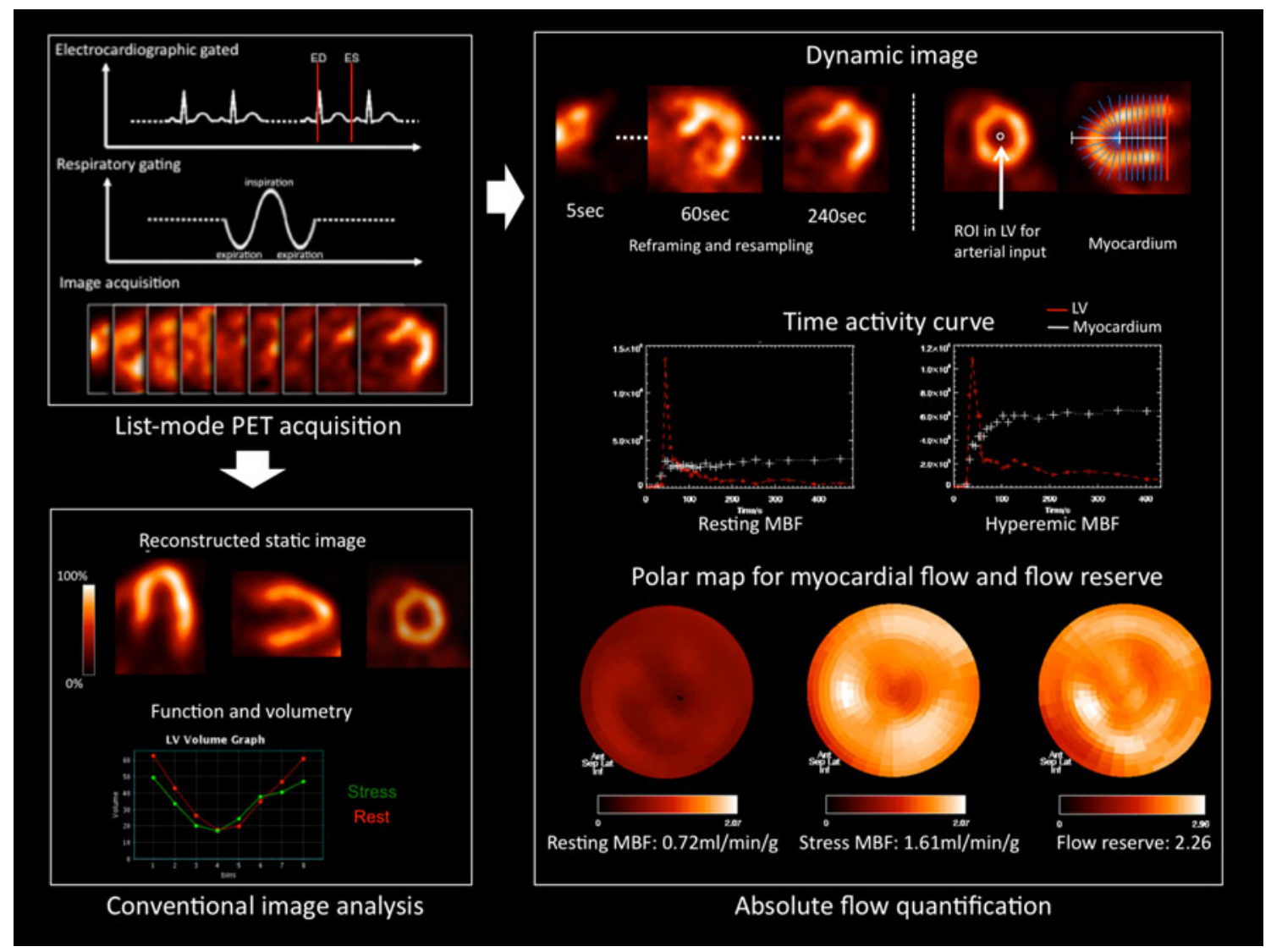

Fig. 1 Schematic display of flow quantification, static perfusion images, and functional assessment from list mode acquisition data by a positron emission tomography (PET) system. List mode acquisition can be started at the same time of tracer injection. Electrocardiographic and respiratory gating signals are sampled in addition to continuous acquisition of images (left upper panel). After acquisition,

Gould et al. [21] evaluated whether intensive cholesterollowering treatment would decrease myocardial perfusion abnormalities in 12 patients with known coronary atherosclerosis. Rest-dipyridamole PET imaging was used to evaluate myocardial perfusion defects. The study showed that myocardial perfusion defects were significantly smaller after a 90-day period with cholesterol-lowering treatment when compared to a control period without cholesterol-lowering treatment $(P<0.05)$.

In patients with advanced coronary artery disease, it is well known that coronary flow reserve is reduced due to the obstructive, flow-limiting nature of macroscopic disease. In this setting, impaired flow reserve has been shown to have prognostic value for predicting adverse outcome [23, 24]. Interestingly, in coronary artery disease, coronary flow reserve may not only be impaired in areas supplied by stenotic vessels, but also in those supplied by non-stenotic vessels [25], emphasizing the incremental value of coronary flow reserve over measurements of atherosclerosis and relative regional perfusion. It has been shown that in the data are re-sampled and re-framed for each image analysis (left lower panel). For flow quantification, a small region of interest is positioned in the left ventricle (LV) and time-activity curves for LV input and myocardium are plotted (right upper panel). Subsequently, tracer kinetic modeling is applied to obtain flow maps under resting and hyperemic stress conditions (right lower panel)

absence of macroscopic coronary artery disease, global flow reserve can be impaired in heart failure as a consequence of microvascular dysfunction. For instance, a reduced coronary flow reserve has been observed in patients with idiopathic cardiomyopathies that was not related to peripheral arterial function [26]. Initially, it was thought that impaired flow in the failing heart, in the absence of coronary stenosis, was secondary to impaired contractile function, increased wall stress and other mechanical factors [27]. More recently, however, the concept of microvascular dysfunction as an independent contributor to the progression of heart failure in cardiomyopathy has been supported by a number of outcome studies [28, 29]. Neglia et al. [28] evaluated whether myocardial blood flow impairment was predictive for adverse events in 67 patients with idiopathic dilated cardiomyopathy. At baseline, patients underwent rest-stress PET imaging protocol with ${ }^{13} \mathrm{NH}_{3}$. During a mean followup of $45 \pm 37$ months, cardiac death was documented in 8 patients and worsening of heart failure in 16 patients. The 
results highlighted that a reduced myocardial blood flow (less than $1.36 \mathrm{ml} / \mathrm{min} / \mathrm{g}$ ) during pharmacological stress was a predictor of adverse cardiac events [28]. Similarly, Cecchi et al. [29] showed that impaired global stress flow and flow reserve as derived from PET imaging were independent predictors of cardiac death, worsening heart failure or sustained ventricular arrhythmias in 51 patients with hypertrophic cardiomyopathy.

\section{Sympathetic innervation in the failing heart}

In addition to myocardial blood flow, the neurohormonal system consisting of the sympathetic nervous system and the renin-angiotensin-aldosterone axis plays an important role in patients with heart failure [4-7].

In patients with a reduced cardiac output, the sympathetic nervous system becomes activated by high-pressure baroreceptors located in the myocardium of the left ventricle (LV), aortic arch and carotid sinus. Subsequently, afferent neuronal signals are transferred from the baroreceptors to cardio-regulatory centers of the central autonomic nervous system, after which the cardiac sympathetic nervous system is triggered. Several effects on the cardiovascular system are caused by the activated sympathetic nervous system, including increased peripheral vasoconstriction and heart rate as well as an improved cardiac contractility [4-7]. Furthermore, a decline in effective renal arterial perfusion leads to activation of the renin-angiotensin-aldosterone axis which plays an evident role in the maintenance of cardiac output by providing positive inotropic and chronotropic support to the dysfunctional heart. Moreover, it aims to preserve systemic arterial blood pressure by sodium and water retention as well as acting directly on arterial smooth muscle cells as a vasoconstrictor.

The function of the sympathetic nervous system is primarily mediated by the production, uptake and release of norepinephrine (neurotransmitter) from the presynaptic cleft. After tyrosine is converted to norepinephrine, two important mechanisms control predominantly the amount of norepinephrine within the presynaptic cleft: the uptake-1 (neuronal) and uptake-2 (non-neuronal) mechanisms. Norepinephrine can be cleared from the synaptic cleft by either the norepinephrine transporter (NET) protein (uptake-1) located at the dilated endings of the sympathetic neuron or the sodium-dependent non-neuronal transport mechanism (uptake-2) located at the post-synaptic site of the cleft. Importantly, in patients with heart failure, these uptake mechanisms of norepinephrine can be used to visualize myocardial sympathetic innervation and activation patterns $[9,30]$.

Myocardial sympathetic innervation and activation can be assessed non-invasively using dedicated imaging protocols with SPECT or PET tracers $[9,30]$. Both SPECT and PET imaging allow non-invasive visualization of regional and global abnormalities in cardiac sympathetic innervation and activation.

\section{Neuronal imaging with SPECT}

Scintigraphic assessment of cardiac sympathetic innervation and activation can be performed with the use of SPECT tracers $[8,30]$. Currently, cardiac sympathetic neuronal imaging has been performed most commonly with radionuclide imaging of the norepinephrine analog metaiodobenzylguanidine (MIBG) labeled with 123-iodine (123-I) [31-33]. Over the last decades, it has been shown that 123-I MIBG represents a safe and reliable SPECT tracer that can be used to depict the sympathetic nerve system in patients with heart failure [31-35]. MIBG represents a false neurotransmitter that can be cleared from the sympathetic cleft by either the uptake-1 (neuronal) or uptake-2 (non-neuronal) mechanisms. Of note, a small amount of MIBG can also be transferred into sympathetic neurons or cardiomyocytes by means of passive diffusion $[8,30]$. 123-I MIBG is suitable for non-invasive mapping of the sympathetic nervous system as it shows resistance to metabolic degradation by monoamine oxidase or catecholo-methyl transferase within the sympathetic neuron, leading to enhanced accumulation of 123-I MIBG within storage vesicles of the neurons. At present, 123-I MIBG images are usually acquired with a two-step protocol at 10-20 min (early imaging) and 3-4 h (delayed imaging) after tracer administration [36]. Planar and SPECT imaging are performed in the early and late phase of the 123-I MIBG imaging protocol. Planar images are usually acquired from the left-anterior oblique view and provide information on global sympathetic innervation pattern (Fig. 2a), whereas tomographic images (SPECT imaging) are used to assess regional abnormalities in cardiac sympathetic innervation (Fig. 2b).

Most commonly, the heart-to-mediastinum (H/M) ratio is determined on planar imaging by dividing the mean counts per pixel within the cardiac region of interest by the mean counts per pixel within the upper mediastinum. Additionally, time-dependent kinetics can be evaluated by means of the myocardial washout; the rate in which 123-I MIBG is washed out of the myocardium. Myocardial 123-I MIBG washout rate reflects the degree of sympathetic activation of the heart [36].

Heart failure patients with severe deprived cardiac sympathetic innervation tend to have worse prognosis when compared to heart failure patients with relatively preserved neuronal integrity [31-33]. Anastasiou-Nana et al. [37] evaluated whether sympathetic nerve imaging 


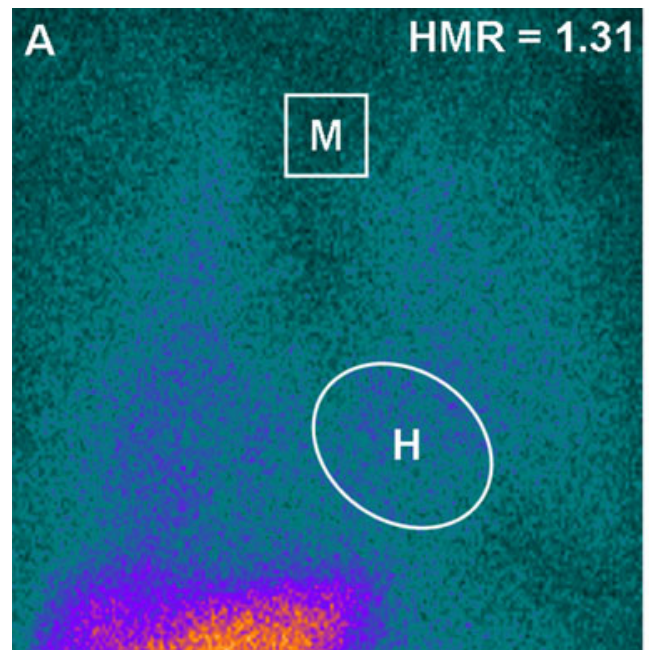

Fig. 2 Cardiac sympathetic nerve imaging with 123-iodine metaiodobenzylguanidine (123-I MIBG) can be used to assess global (panel $A$ ) and regional (panel B) sympathetic innervation in patients with heart failure. a Global reduction of 123-I MIBG uptake (sympathetic denervation) in a patient with advanced heart failure. The heart-tomediastinum $(\mathrm{H} / \mathrm{M})$ ratio on late planar imaging was calculated by

with 123-I MIBG was predictive for adverse events in 52 patients with heart failure. MIBG uptake on planar imaging (HR $0.017,95 \%$ CI $0.00-0.79, P=0.038$ ) was a predictor for all-cause mortality, in addition to peak oxygen consumption (HR $0.83,95 \%$ CI $0.70-0.98, P=0.031$ ) and pulmonary capillary wedge pressure (HR $1.06,95 \%$ CI $1.00-1.12, P=0.038$ ). Furthermore, studies have also shown that the rate in which 123-I MIBG is washout out of the myocardium is important for prognostication of patients with heart failure [38-40].

Recently, the AdreView Myocardial Imaging for Risk Evaluation in Heart Failure (ADMIRE-HF) trial evaluated the prognostic value of cardiac 123-I MIBG imaging in 961 patients with heart failure [33]. All subjects underwent cardiac 123-I MIBG planar and SPECT imaging as well as myocardial perfusion imaging with ${ }^{99 \mathrm{~m}} \mathrm{Tc}$-tetrofosmin. Patients were monitored until they reached the pre-determined follow-up period of 2 years or until adverse major cardiac events were documented; progression of heart failure, potentially lethal arrhythmias or cardiac death. Patients with adverse events showed significantly lower early and late $\mathrm{H} / \mathrm{M}$ ratio $(P<0.01)$ as well as higher myocardial washout rate $(P<0.01)$ than patients without adverse events during follow-up. Most important, the risk for major cardiac events was significantly lower in patients with $\mathrm{H} / \mathrm{M}$ ratio $\geq 1.60$ when compared to patients with H/M ratio $<1.60$ (HR 0.40, 95\% CI 0.25-0.64, $P<0.01$ ) (Fig. 3). Accordingly, this study confirmed the previously reported predictive value of cardiac 123-I MIBG imaging in patients with heart failure.

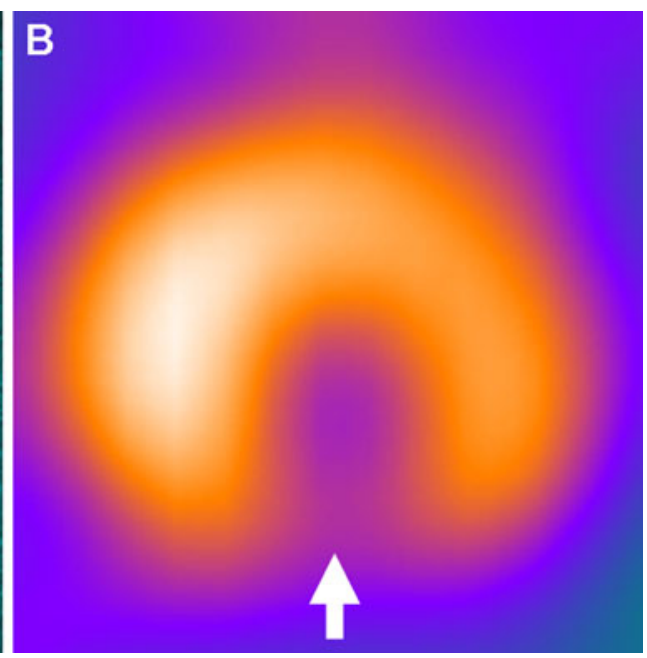

dividing the mean counts per pixel within the heart $(\mathrm{H})$ by the mean counts per pixel within the upper mediastinum (M). In this example, the late $\mathrm{H} / \mathrm{M}$ ratio was 1.31 . b An example of regional abnormalities in sympathetic innervation is illustrated below (as indicated by regional defect in 123-I MIBG uptake, white arrow)

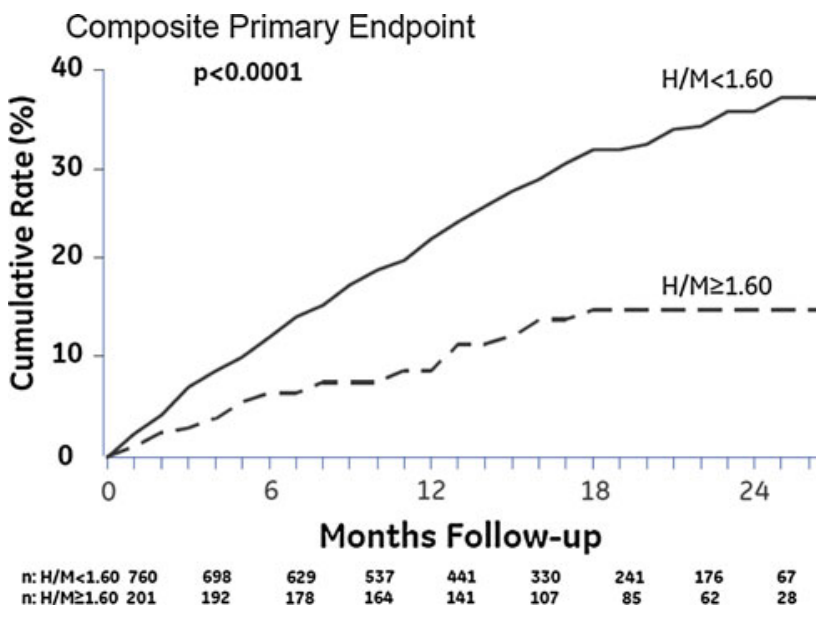

Fig. 3 Cumulative event rates for heart failure patients with heart-tomediastinum $(\mathrm{H} / \mathrm{M})$ ratio $<1.60$ and patients with $\mathrm{H} / \mathrm{M}$ ratio $\geq 1.60$ on late planar 123-iodine metaiodobenzylguanidine (123-I MIBG) imaging. The composite primary endpoint of heart failure progression, potential lethal arrhythmic events or cardiac death was significantly more documented in patients with late $\mathrm{H} / \mathrm{M}$ ratio $<1.60$ when compared to patients with late $\mathrm{H} / \mathrm{M}$ ratio $\geq 1.60$ at 2 -year of follow-up (38 vs. $15 \%, P<0.01$ ). Reprinted with permission from reference 33

Sympathetic denervation of the myocardium is also thought to play an evident role in the development of lifethreatening ventricular arrhythmias and sudden arrhythmic death $[41,42]$. Viable myocardium with deprived sympathetic innervation may serve as a substrate for ventricular arrhythmias as these regions show an increased automaticity and triggering to external sympathetic stimuli, when 
compared to viable regions with preserved neuronal integrity [41, 42]. To date, several studies have explored the role of cardiac 123-I MIBG imaging for prediction of ventricular arrhythmias, sudden cardiac death, or appropriate implantable cardioverter-defibrillator (ICD) discharge [33, 43-47]. In 961 patients with heart failure, Jacobson et al. [33] demonstrated that patients with preserved myocardial sympathetic innervation (H/M ratio $\geq 1.60$ ) had significantly less arrhythmic events when compared to patients depressed sympathetic innervation $(\mathrm{H} / \mathrm{M}$ ratio $<1.60) \quad(\mathrm{HR} \quad 0.37,95 \%$ CI $0.16-0.85$, $P=0.02)$ during a median follow-up of 17 months. In addition, regional abnormalities in sympathetic innervation are also likely to play a role in the development of ventricular tachyarrhythmias [43, 47]. The role of cardiac sympathetic nerve imaging with 123-I MIBG was also evaluated in 116 patients with advanced heart failure who were clinically referred for ICD implantation [47]. Patients with ventricular arrhythmias causing appropriate ICD discharge (primary endpoint) showed significantly more regional sympathetic denervation (as expressed in summed 123-I MIBG SPECT defect score) when compared to patients without appropriate ICD discharge $(P<0.05)$ (Fig. 4). Moreover, late 123-I MIBG SPECT defect score was independently associated with the occurrence of appropriate ICD discharges (HR 1.13, 95\% CI 1.05-1.21, $P<0.01)$.

Beyond regional sympathetic denervation, it has been suggested that hyperactivity of the cardiac sympathetic nervous system (increased sympathetic tone) is associated with the occurrence of potential lethal ventricular arrhythmias and sudden cardiac death [45, 48]. Moreover, it has been demonstrated that enhanced activation of beta-adrenergic receptors within the myocardium, which results from a chronic up-regulated sympathetic tone, could initiate ventricular tachycardia via non-reentrant mechanisms in heart failure patients [49]. An important study was performed by Tamaki and colleagues [45] who sought to determine the value of cardiac 123-I MIBG imaging for prediction of sudden arrhythmic death in 106 outpatients with chronic heart failure and LV ejection fraction (LVEF) $<40 \%$. Patients with sudden cardiac death showed significantly lower early (1.72 \pm 0.29 vs. $1.87 \pm 0.26, P=$ $0.036)$ and late $(1.54 \pm 0.25$ vs. $1.76 \pm 0.31, P<0.01)$ $\mathrm{H} / \mathrm{M}$ ratio as well as significantly higher myocardial washout rate $(39.9 \pm 15.2 \%$ vs. $27.6 \pm 14.2 \%, P<0.01)$, than patients who survived the mean follow-up of $65 \pm 31$ months, as depicted in Fig. 5. Importantly, only myocardial washout rate $(\mathrm{HR}=1.052,95 \% \mathrm{CI}$

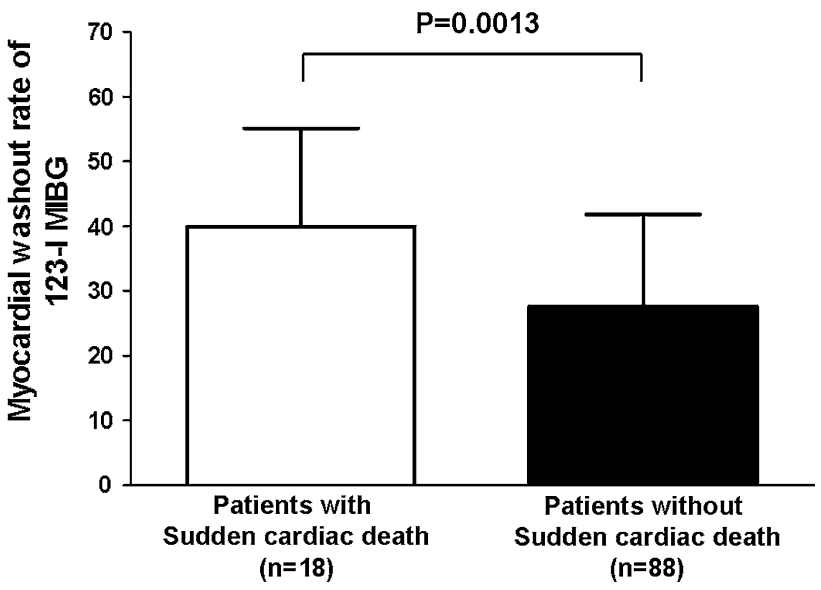

Fig. 5 Cardiac 123-iodine metaiodobenzylguanidine (123-I MIBG) planar imaging in patients with $(n=18)$ and without $(n=88)$ sudden cardiac death. Myocardial washout rate was significantly higher in patients with sudden cardiac death when compared to patients without sudden cardiac death $(39.9 \pm 15.2 \%$ vs. $27.6 \pm 14.2 \%, P=0.0013)$ during a mean follow-up period of $65 \pm 31$ months. Data were based on reference 45
Fig. 4 Cardiac 123-iodine metaiodobenzylguanidine (123-I MIBG) imaging allows prediction of ventricular arrhythmias causing appropriate implantable cardioverterdefibrillator (ICD) therapy in heart failure patients. Patients with a large defect on late 123-I MIBG SPECT imaging (summed defect score $>26$ ) showed significantly more ventricular arrhythmias when compared to patients with a small defect on late 123-I MIBG SPECT imaging (summed defect score $\leq 26$ ) at 3-year of follow-up (52 vs. 5\%, $P<0.01)$. Reprinted with permission from reference 47

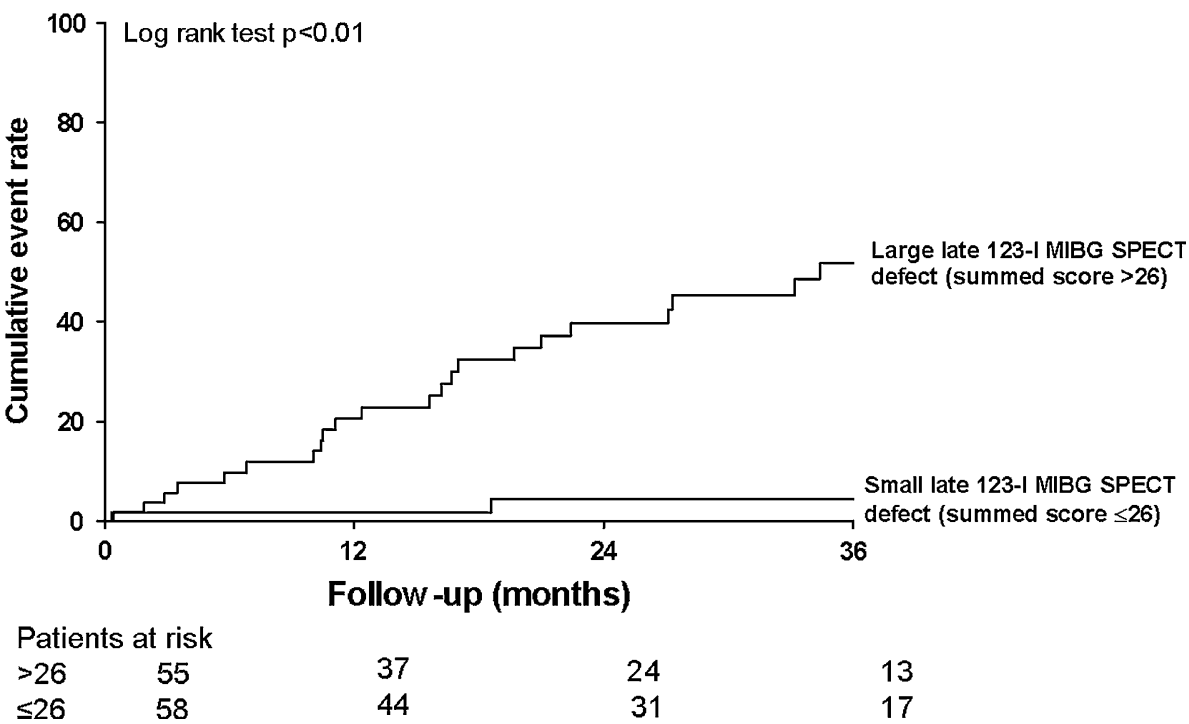


1.020-1.085, $P<0.01)$ and LVEF $(\mathrm{HR}=0.930,95 \% \mathrm{CI}$ $0.870-0.995, P=0.0341)$ were independent predictors for sudden arrhythmic death.

One issue that needs to be addressed is the existing heterogeneity of data acquisition and image analyses among the available 123-I MIBG studies. Standardization of data acquisition and post-processing techniques may further contribute to clinical implementation of cardiac 123-I MIBG imaging for prognostication of heart failure patients [36].

\section{Neuronal imaging with PET}

PET represents a highly dedicated scintigraphic technique to map the cardiac sympathetic nervous system, with superior spatial and temporal resolution when compared to SPECT imaging [9]. With the currently applied PET scanners and post-processing algorithms, images can be reconstructed with a spatial resolution of 4-7 $\mathrm{mm}$. Moreover, its relatively high temporal resolution allows the development of dynamic images which can be used to assess tracer kinetics. Importantly, with the use of validated photon attenuation and scatter correction algorithms, PET imaging can be used to quantify the absolute amount of nuclear tracer within the myocardium and its time-dependent kinetics [9].

At present, a wide variety of PET tracers allow assessment of sympathetic innervation and activation of the heart. Basically, available PET tracers are divided into (1) radiolabeled catecholamines and (2) radiolabeled catecholamine analogs. Radiolabeled catecholamines are molecular identical to endogenous neurotransmitters, and therefore, they will undergo similar uptake, release and metabolic pathways within the myocardium and sympathetic neurons, whereas the radiolabeled catecholamine analogs (also referred to as false neurotransmitters) follow the same uptake and release mechanisms, without being metabolized like the endogenous transmitters. Hydroxyephedrine labeled with carbon-11 $\left({ }^{11} \mathrm{C}\right.$-HED) represents one of the most frequently applied PET tracer for cardiac sympathetic nerve imaging as it shows high affinity for the uptake-1 transporter located on the presynaptic nerve terminal. In addition, ${ }^{11} \mathrm{C}-\mathrm{HED}$ can be used for accurate assessment of regional neuronal defects as it has been shown to distribute equally within the myocardium in physiologic conditions. Thus far, several studies have aimed to describe sympathetic neuronal defects in heart failure patients using PET imaging with ${ }^{11} \mathrm{C}-\mathrm{HED}$ [50-56]. Hartmann et al. [51] have assessed cardiac sympathetic innervation patterns in 29 patients with severely dilated cardiomyopathy and heart failure as well as in 8 healthy volunteers. Gated blood-pool imaging was performed to obtain LV systolic function. In all patients, the PET imaging protocol consisted of a resting perfusion scan with ${ }^{13} \mathrm{NH}_{3}$ combined with a dynamic PET scan using ${ }^{11} \mathrm{C}-\mathrm{HED}$. The study demonstrated that global retention of ${ }^{11} \mathrm{C}$-HED was significantly lower in patients diagnosed with heart failure when compared to the healthy control patients $(6.2$ (1.6) $\% / \mathrm{min}$ vs. $10.7(1.0) \% / \mathrm{min}, P<0.01)$. Moreover, PET imaging was also able to detect significant regional neuronal defects in apical $(P<0.01)$ and inferoapical $(P<0.05)$ myocardial segments of patients with heart failure. In these segments, the ${ }^{11} \mathrm{C}-\mathrm{HED} /$ perfusion ratio showed a progressive and significant $(P<0.05)$ decline when compared to the basal cardiac segments.

Cardiac innervation has also been explored in heart failure patients who underwent cardiac transplantation; in particular, re-innervation was demonstrated after transplantation. Bengel et al. [54] evaluated cardiac sympathetic innervation in 27 asymptomatic patients with previous orthotopic heart transplantation. With ${ }^{11} \mathrm{C}$-HED PET imaging, cardiac sympathetic re-innervation was observed in 14 of the 27 patients. Di Carli et al. [57] performed another study that evaluated cardiac sympathetic innervation in patients with previous cardiac transplants. In total, 14 patients underwent PET imaging with ${ }^{11} \mathrm{C}$-HED. The results indicated that sympathetic uptake of ${ }^{11} \mathrm{C}-\mathrm{HED}$ was significantly higher in the territory served by the leftanterior descending artery when compared to those served by the right coronary artery or circumflex artery.

In addition, neuronal imaging with PET has also been used to evaluate the relation between cardiac sympathetic innervation and ventricular arrhythmias [58]. In 11 pigs, myocardial infarction was induced by balloon occlusion of the left-anterior descending coronary artery. Subsequently, PET imaging was performed to evaluate myocardial perfusion and sympathetic innervation of the myocardium. Invasive electrophysiological testing was performed to evaluate the inducibility of ventricular arrhythmias. Animals with inducible ventricular tachycardia showed a larger perfusion/innervation mismatch when compared to animals without inducible ventricular tachycardia (10 \pm $4 \%$ vs. $4 \pm 2 \%, P=0.02$ ). Furthermore, the extent of perfusion/innervation mismatch was significantly correlated to reduced myocardial voltage $(r=0.93, P=0.001)$ and the site of earliest ventricular tachycardia (chi-square 13.1, $P<0.001)$.

\section{Future role of nuclear imaging in heart failure}

While myocardial blood flow and neuronal imaging are increasingly used in clinical cardiology, a variety of molecular-targeted tracers is being evaluated on the preclinical level. These preclinical tracers have in common that they target key mechanisms involved in (1) early 
development of heart failure and (2) novel therapeutic interventions for heart failure. It is expected that ongoing efforts that aim to establish these advanced molecular imaging techniques will lead to the transition from preclinical to clinical use in the near future.

\section{Nuclear imaging for prevention of overt heart failure}

Insight into the underlying mechanisms involved in the transition from regional ischemia and infarction toward global heart failure, i.e., LV remodeling, may substantially improve the prevention of overt organ failure. In this perspective, targeted visualization of biomechanisms involved in cardiac remodeling may help to identify individuals at risk for progression of ventricular dysfunction in an early phase. It has been recognized that matrix metalloproteinases (MMPs), which are proteolytic enzymes, play an important role in remodeling of the heart [59]. For example, Mukherjee et al. [60] demonstrated a reduction of postmyocardial LV dilatation and expansion of myocardial infarction by MMP inhibition in pigs. Furthermore, imaging of MMP upregulation after myocardial infarction was reported by $\mathrm{Su}$ et al. [61]. This study demonstrated a fivefold increased uptake of an MMP-targeted tracer (In-111 RP782) within the infarct area and a twofold increase in remote areas in a rodent model of myocardial infarction.

In addition, cardiac remodeling has also been linked to other biomechanisms, including myocardial substrate utilization [62], sympathetic nervous system [63], reninaldosterone-angiotensin system [64], adhesion molecules such as alphavbeta3 integrin [65, 66], and growth factors such as VEGF [67]. All of these mechanisms seem to be activated early after myocardial infarction, and they are thought to contribute to ongoing deterioration of ventricular function. The hope is that non-invasive visualization of patterns of activation early after infarction will allow to predict individual risk for remodeling, and to guide specific therapy directed against these processes [68]. Accordingly, these dedicated imaging techniques may allow more effective prevention of heart failure in the future.

\section{Nuclear imaging for monitoring molecular} interventions

Advances in the understanding of heart failure etiology and pathophysiology have led to the introduction of novel molecular interventions for patients with heart failure, such as gene and cell therapy. These novel interventions have entered the therapeutic arena to provide treatment solutions based on specific disease mechanisms. However, despite the fact that these novel therapies are promising, some basic principles are currently still not well-understood. For instance, several important methodological issues regarding appropriate therapeutic strategy (e.g., timing, dose and route) as well as the type of study endpoints need to be addressed in additional studies.

In patients with heart failure, efficient cell engraftment and subsequent cell survival are of high importance for the success rate of cell transplantation therapies. At present, several techniques for visualization and monitoring of transplanted cells in the heart have been proposed. The most straightforward approach is direct labeling of cells prior to their application with an agent that can be detected by an in vivo imaging system. Currently, therapeutic cells have already been labeled with paramagnetic substances such as iron oxides for magnetic resonance imaging [69], and with radionuclides such as In-111 oxin [70] and 18Ffluorodeoxyglucose $\left({ }^{18} \mathrm{~F}-\mathrm{FDG}\right)$ [71] for nuclear imaging. An example image of preclinical studies using ${ }^{18} \mathrm{~F}$-FDGlabeled cardiac derived stem cells in rat infarction model is shown in Fig. 6. This technique allows the visualization of location and survival of delivered cells and myocardial perfusion in the same imaging session. Despite its high sensitivity, the half-life of radiotracers $\left({ }^{111}\right.$ In is $67 \mathrm{~h}$, and

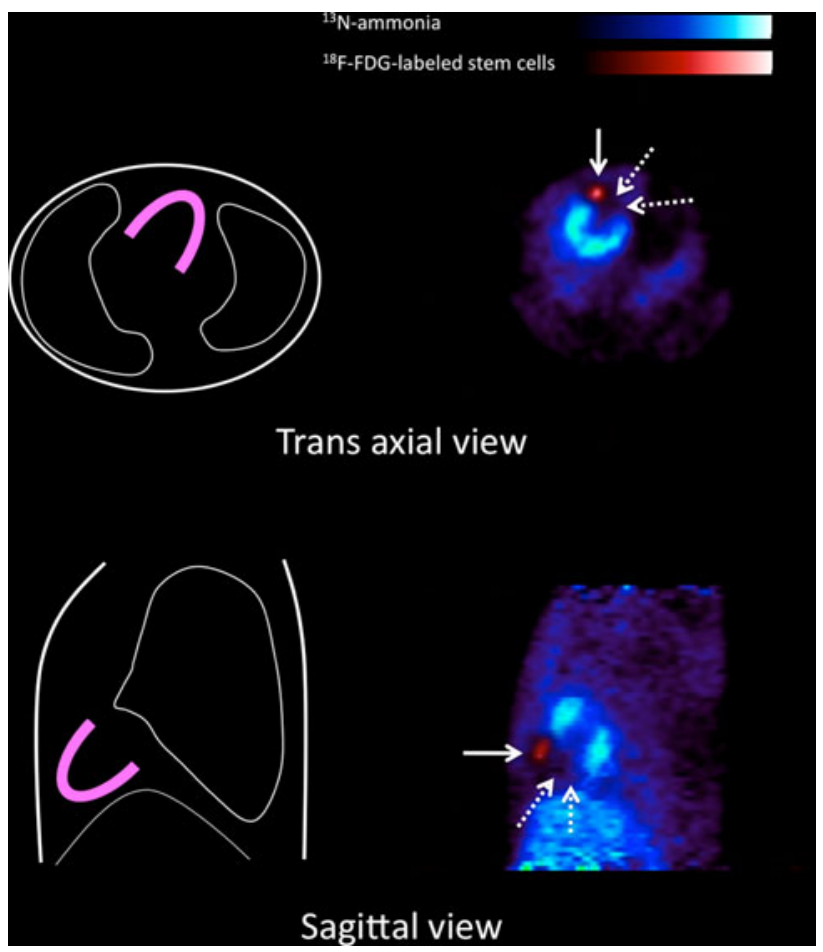

Fig. 6 Fused positron emission tomography (PET) images of 18Ffluorodeoxyglucose $\left({ }^{18} \mathrm{~F}-\mathrm{FDG}\right)$-labeled stem cells (solid arrows) and $\mathrm{N}-13$ Ammonia $\left({ }^{13} \mathrm{NH}_{3}\right)$ myocardial perfusion in rat infarction model. Radiolabeled stem cells were administrated intramyocardially into the infracted region. Subsequently, FDG images confirmed the orientation and survival of delivered cells (solid arrow) with the reference of ammonia perfusion image which showed a large defect in the anterior region (dotted arrows) 
${ }^{18} \mathrm{~F}$ is $110 \mathrm{~min}$ ) discourages from long-term fate of delivered cells.

Another approach for monitoring transplanted cells is reporter gene imaging, which has been introduced initially for specific monitoring of the transfer and expression of exogenous genes in the myocardium [72]. The donor cells are genetically modified to express reporter gene prior to in vivo transplantation. Imaging requires stable transduction of genes after cell transplantation, thereby encoding gene products that mediate accumulation of a radioactive reporter probe within the donor cell. The reporter gene will be continuously expressed as long as cells are viable, but will be silent after cell death. Therefore, imaging of the reporter mediated tracer accumulation provides a specific signal for longer-term graft cell survival [73]. Thus far, several experimental studies have proofed the principle of reporter gene imaging of transplanted cells [73, 74].

These techniques for cell tracking can be used to obtain valuable insights into determinants of cell engraftment; the presence of a low number of engrafted cells could explain the limited success of the particular procedure. Using direct cell labeling and quantification, it has recently been shown that a large fraction of cells is already lost very early after injection into the myocardium [75]. Subsequently, several techniques to mechanically retain the cells in the myocardium (such as e.g., sealing of the injection site with fibrin glue) have been suggested, and those may be beneficial for the success of cell therapy in the future.

The success of each of these novel molecular imaging methodologies will depend on the clinical success of each of the respective molecular therapeutic intervention. It is likely, however, that efforts in molecular imaging and therapy in general will both contribute to the advances in heart failure treatment and prevention.

\section{Summary}

Heart failure represents an important pathophysiologic condition with markedly increased morbidity and mortality rates over the last decades. Myocardial blood flow and perfusion have been identified as important parameters in patients with heart failure. Nuclear imaging with SPECT is routinely used, but PET allows absolute for the quantification of myocardial blood flow beyond the assessment of relative myocardial perfusion, which may be beneficial, in specific patients. Both PET and SPECT can be used for diagnosis, treatment options, and prognosis in patients with heart failure.

Cardiac sympathetic innervation is also important in patients with heart failure. SPECT imaging with 123-I MIBG permits visualization of cardiac sympathetic innervation of the failing heart. Abnormal sympathetic innervation and activation, as assessed with 123-I MIBG is predictive of cardiac mortality, morbidity, and ventricular arrhythmias or sudden cardiac death in patients with heart failure. Accordingly, cardiac 123-I MIBG imaging will be important for prognosis in patients with heart failure.

Recent emphasis is put on the development of novel nuclear imaging techniques that will target specific biologic processes of the failing heart. These molecular-targeted imaging techniques will provide further insight into the pathophysiology of the failing heart and may potentially be used for early detection of heart failure as well as monitoring new therapeutic interventions.

Acknowledgments Mark J. Boogers is supported by the Dutch Heart Foundation grant number 2006T102. Kenji Fukushima is supported by Wagner-Trizuka grant from society of nuclear medicine. Jeroen J. Bax received research grants from Medtronic, Boston Scientific, Biotronik, Edwards Lifesciences, BMS medical imaging, St. Jude Medical and GE Healthcare.

Open Access This article is distributed under the terms of the Creative Commons Attribution Noncommercial License which permits any noncommercial use, distribution, and reproduction in any medium, provided the original author(s) and source are credited.

\section{References}

1. Hunt SA, Abraham WT, Chin MH, Feldman AM, Francis GS, Ganiats TG, Jessup M, Konstam MA, Mancini DM, Michl K, Oates JA, Rahko PS, Silver MA, Stevenson LW, Yancy CW (2009) 2009 focused update incorporated into the ACC/AHA 2005 Guidelines for the Diagnosis and Management of Heart Failure in Adults: a report of the American College of Cardiology Foundation/American Heart Association Task Force on Practice Guidelines: developed in collaboration with the International Society for Heart and Lung Transplantation. Circulation 119: 391-479

2. Rosamond W, Flegal K, Furie K, Go A, Greenlund K, Haase N, Hailpern SM, Ho M, Howard V, Kissela B, Kittner S, LloydJones D, McDermott M, Meigs J, Moy C, Nichol G, O’Donnell C, Roger V, Sorlie P, Steinberger J, Thom T, Wilson M, Hong Y (2008) Heart disease and stroke statistics - 2008 update: a report from the American Heart Association Statistics Committee and Stroke Statistics Subcommittee. Circulation 117:25-146

3. Levy D, Kenchaiah S, Larson MG, Benjamin EJ, Kupka MJ, Ho KK, Murabito JM, Vasan RS (2002) Long-term trends in the incidence of and survival with heart failure. N Engl J Med 347:1397-1402

4. Bristow MR (1984) The adrenergic nervous system in heart failure. N Engl J Med 311:850-851

5. Braunwald E, Fauci AS, Kasper DL, Hauser SL, Longo DL, Jameson JL (2001) Principles of internal medicine. Harrison's 15:1316-1323

6. Mann DL, Bristow MR (2005) Mechanisms and models in heart failure: the biomechanical model and beyond. Circulation 111:2837-2849

7. Triposkiadis F, Karayannis G, Giamouzis G, Skoularigis J, Louridas G, Butler J (2009) The sympathetic nervous system in heart failure physiology, pathophysiology, and clinical implications. J Am Coll Cardiol 54:1747-1762 
8. Flotats A, Carrio I (2004) Cardiac neurotransmission SPECT imaging. J Nucl Cardiol 11:587-602

9. Bengel FM, Higuchi T, Javadi MS, Lautamaki R (2009) Cardiac positron emission tomography. J Am Coll Cardiol 54:1-15

10. Hendel RC, Berman DS, Di Carli MF, Heidenreich PA, Henkin RE, Pellikka PA, Pohost GM, Williams KA (2009) ACCF/ ASNC/ACR/AHA/ASE/SCCT/SCMR/SNM 2009 appropriate use criteria for cardiac radionuclide imaging: a report of the American College of Cardiology Foundation Appropriate Use Criteria Task Force, the American Society of Nuclear Cardiology, the American College of Radiology, the American Heart Association, the American Society of Echocardiography, the Society of Cardiovascular Computed Tomography, the Society for Cardiovascular Magnetic Resonance, and the Society of Nuclear Medicine. Circulation 119:561-587

11. Underwood SR, Anagnostopoulos C, Cerqueira M, Ell PJ, Flint EJ, Harbinson M, Kelion AD, Al-Mohammad A, Prvulovich EM, Shaw LJ, Tweddel AC (2004) Myocardial perfusion scintigraphy: the evidence. Eur J Nucl Med Mol Imaging 31:261-291

12. Di Carli MF, Dorbala S, Meserve J, El FG, Sitek A, Moore SC (2007) Clinical myocardial perfusion PET/CT. J Nucl Med 48:783-793

13. Higuchi T, Nekolla SG, Huisman MM, Reder S, Poethko T, Yu M, Wester HJ, Casebier DS, Robinson SP, Botnar RM, Schwaiger M (2008) A new 18F-labeled myocardial PET tracer: myocardial uptake after permanent and transient coronary occlusion in rats. J Nucl Med 49:1715-1722

14. Nekolla SG, Reder S, Saraste A, Higuchi T, Dzewas G, Preissel A, Huisman M, Poethko T, Schuster T, Yu M, Robinson S, Casebier D, Henke J, Wester HJ, Schwaiger M (2009) Evaluation of the novel myocardial perfusion positron-emission tomography tracer 18F-BMS-747158-02: comparison to $13 \mathrm{~N}$-ammonia and validation with microspheres in a pig model. Circulation 119: 2333-2342

15. Yoshida K, Mullani N, Gould KL (1996) Coronary flow and flow reserve by PET simplified for clinical applications using rubidium-82 or nitrogen-13-ammonia. J Nucl Med 37:1701-1712

16. Lautamaki R, George RT, Kitagawa K, Higuchi T, Merrill J, Voicu C, DiPaula A, Nekolla SG, Lima JA, Lardo AC, Bengel FM (2009) Rubidium-82 PET-CT for quantitative assessment of myocardial blood flow: validation in a canine model of coronary artery stenosis. Eur J Nucl Med Mol Imag 36:576-586

17. Nitzsche EU, Choi Y, Czernin J, Hoh CK, Huang SC, Schelbert HR (1996) Noninvasive quantification of myocardial blood flow in humans. A direct comparison of the $[13 \mathrm{~N}] \mathrm{ammonia}$ and the [15O]water techniques. Circulation 93:2000-2006

18. Gerber BL, Melin JA, Bol A, Labar D, Cogneau M, Michel C, Vanoverschelde JL (1998) Nitrogen-13-ammonia and oxygen-15water estimates of absolute myocardial perfusion in left ventricular ischemic dysfunction. J Nucl Med 39:1655-1662

19. El FG, Kardan A, Sitek A, Dorbala S, bi-Hatem N, Lahoud Y, Fischman A, Coughlan M, Yasuda T, Di Carli MF (2009) Reproducibility and accuracy of quantitative myocardial blood flow assessment with (82)Rb PET: comparison with (13)Nammonia PET. J Nucl Med 50:1062-1071

20. Czernin J, Muller P, Chan S, Brunken RC, Porenta G, Krivokapich J, Chen K, Chan A, Phelps ME, Schelbert HR (1993) Influence of age and hemodynamics on myocardial blood flow and flow reserve. Circulation 88:62-69

21. Gould KL, Martucci JP, Goldberg DI, Hess MJ, Edens RP, Latifi R, Dudrick SJ (1994) Short-term cholesterol lowering decreases size and severity of perfusion abnormalities by positron emission tomography after dipyridamole in patients with coronary artery disease. A potential noninvasive marker of healing coronary endothelium. Circulation 89:1530-1538
22. Kaufmann PA, Gnecchi-Ruscone T, di TM, Schafers KP, Luscher TF, Camici PG (2000) Coronary heart disease in smokers: vitamin $\mathrm{C}$ restores coronary microcirculatory function. Circulation 102:1233-1238

23. Herzog BA, Husmann L, Valenta I, Gaemperli O, Siegrist PT, Tay FM, Burkhard N, Wyss CA, Kaufmann PA (2009) Longterm prognostic value of $13 \mathrm{~N}$-ammonia myocardial perfusion positron emission tomography added value of coronary flow reserve. J Am Coll Cardiol 54:150-156

24. Tio RA, Dabeshlim A, Siebelink HM, De SJ, Hillege HL, Zeebregts CJ, Dierckx RA, van Veldhuisen DJ, Zijlstra F, Slart RH (2009) Comparison between the prognostic value of left ventricular function and myocardial perfusion reserve in patients with ischemic heart disease. J Nucl Med 50:214-219

25. van den Heuvel AF, van Veldhuisen DJ, van der Wall EE, Blanksma PK, Siebelink HM, Vaalburg WM, van Gilst WH, Crijns HJ (2000) Regional myocardial blood flow reserve impairment and metabolic changes suggesting myocardial ischemia in patients with idiopathic dilated cardiomyopathy. J Am Coll Cardiol 35:19-28

26. Stolen KQ, Kemppainen J, Kalliokoski KK, Karanko H, Toikka J, Janatuinen T, Raitakari OT, Airaksinen KE, Nuutila P, Knuuti J (2004) Myocardial perfusion reserve and peripheral endothelial function in patients with idiopathic dilated cardiomyopathy. Am J Cardiol 93:64-68

27. Weiss MB, Ellis K, Sciacca RR, Johnson LL, Schmidt DH, Cannon PJ (1976) Myocardial blood flow in congestive and hypertrophic cardiomyopathy: relationship to peak wall stress and mean velocity of circumferential fiber shortening. Circulation 54:484-494

28. Neglia D, Michelassi C, Trivieri MG, Sambuceti G, Giorgetti A, Pratali L, Gallopin M, Salvadori P, Sorace O, Carpeggiani C, Poddighe R, L'Abbate A, Parodi O (2002) Prognostic role of myocardial blood flow impairment in idiopathic left ventricular dysfunction. Circulation 105:186-193

29. Cecchi F, Olivotto I, Gistri R, Lorenzoni R, Chiriatti G, Camici PG (2003) Coronary microvascular dysfunction and prognosis in hypertrophic cardiomyopathy. N Engl J Med 349:1027-1035

30. Langer O, Halldin C (2002) PET and SPET tracers for mapping the cardiac nervous system. Eur J Nucl Med Mol Imag 29: 416-434

31. Agostini D, Verberne HJ, Burchert W, Knuuti J, Povinec P, Sambuceti G, Unlu M, Estorch M, Banerjee G, Jacobson AF (2008) I-123-mIBG myocardial imaging for assessment of risk for a major cardiac event in heart failure patients: insights from a retrospective European multicenter study. Eur J Nucl Med Mol Imag 35:535-546

32. Verberne HJ, Brewster LM, Somsen GA, Van Eck-Smit BL (2008) Prognostic value of myocardial 123I-metaiodobenzylguanidine (MIBG) parameters in patients with heart failure: a systematic review. Eur Heart J 29:1147-1159

33. Jacobson AF, Senior R, Cerqueira MD, Wong ND, Thomas GS, Lopez VA, Agostini D, Weiland F, Chandna H, Narula J (2010) Myocardial Iodine-123 Meta-Iodobenzylguanidine Imaging and Cardiac Events in Heart Failure Results of the Prospective ADMIRE-HF (AdreView Myocardial Imaging for Risk Evaluation in Heart Failure) Study. J Am Coll Cardiol 55:2212-2221

34. Merlet P, Valette H, Dubois-Rande JL, Moyse D, Duboc D, Dove P, Bourguignon MH, Benvenuti C, Duval AM, Agostini D (1992) Prognostic value of cardiac metaiodobenzylguanidine imaging in patients with heart failure. J Nucl Med 33:471-477

35. Merlet P, Benvenuti C, Moyse D, Pouillart F, Dubois-Rande JL, Duval AM, Loisance D, Castaigne A, Syrota A (1999) Prognostic value of MIBG imaging in idiopathic dilated cardiomyopathy. J Nucl Med 40:917-923 
36. Flotats A, Carrio I, Agostini D, Le GD, Marcassa C, Schaffers M, Somsen GA, Unlu M, Verberne HJ (2010) Proposal for standardization of 123I-metaiodobenzylguanidine (MIBG) cardiac sympathetic imaging by the EANM Cardiovascular Committee and the European Council of Nuclear Cardiology. Eur J Nucl Med Mol Imag 37:1802-1812

37. Anastasiou-Nana MI, Terrovitis JV, Athanasoulis T, Karaloizos L, Geramoutsos A, Pappa L, Tsagalou EP, Efentakis S, Nanas JN (2005) Prognostic value of iodine-123-metaiodobenzylguanidine myocardial uptake and heart rate variability in chronic congestive heart failure secondary to ischemic or idiopathic dilated cardiomyopathy. Am J Cardiol 96:427-431

38. Momose M, Kobayashi H, Iguchi N, Matsuda N, Sakomura Y, Kasanuki H, Kusakabe K, Okawa T (1999) Comparison of parameters of 123I-MIBG scintigraphy for predicting prognosis in patients with dilated cardiomyopathy. Nucl Med Commun 20:529-535

39. Ogita H, Shimonagata T, Fukunami M, Kumagai K, Yamada T, Asano Y, Hirata A, Asai M, Kusuoka H, Hori M, Hoki N (2001) Prognostic significance of cardiac (123)I metaiodobenzylguanidine imaging for mortality and morbidity in patients with chronic heart failure: a prospective study. Heart 86:656-660

40. Yamada T, Shimonagata T, Fukunami M, Kumagai K, Ogita H, Hirata A, Asai M, Makino N, Kioka H, Kusuoka H, Hori M, Hoki N (2003) Comparison of the prognostic value of cardiac iodine123 metaiodobenzylguanidine imaging and heart rate variability in patients with chronic heart failure: a prospective study. J Am Coll Cardiol 41:231-238

41. Podrid PJ, Fuchs T, Candinas R (1990) Role of the sympathetic nervous system in the genesis of ventricular arrhythmia. Circulation 82:103-113

42. Kammerling JJ, Green FJ, Watanabe AM, Inoue H, Barber MJ, Henry DP, Zipes DP (1987) Denervation supersensitivity of refractoriness in noninfarcted areas apical to transmural myocardial infarction. Circulation 76:383-393

43. Schafers M, Wichter T, Lerch H, Matheja P, Kuwert T, Schafers K, Borggrefe M, Breithardt G, Schober O (1999) Cardiac 123IMIBG uptake in idiopathic ventricular tachycardia and fibrillation. J Nucl Med 40:1-5

44. Paul M, Schafers M, Kies P, Acil T, Schafers K, Breithardt G, Schober O, Wichter T (2006) Impact of sympathetic innervation on recurrent life-threatening arrhythmias in the follow-up of patients with idiopathic ventricular fibrillation. Eur J Nucl Med Mol Imag 33:866-870

45. Tamaki S, Yamada T, Okuyama Y, Morita T, Sanada S, Tsukamoto Y, Masuda M, Okuda K, Iwasaki Y, Yasui T, Hori M, Fukunami M (2009) Cardiac iodine-123 metaiodobenzylguanidine imaging predicts sudden cardiac death independently of left ventricular ejection fraction in patients with chronic heart failure and left ventricular systolic dysfunction: results from a comparative study with signal-averaged electrocardiogram, heart rate variability, and QT dispersion. J Am Coll Cardiol 53:426-435

46. Nagahara D, Nakata T, Hashimoto A, Wakabayashi T, Kyuma M, Noda R, Shimoshige S, Uno K, Tsuchihashi K, Shimamoto K (2008) Predicting the need for an implantable cardioverter defibrillator using cardiac metaiodobenzylguanidine activity together with plasma natriuretic peptide concentration or left ventricular function. J Nucl Med 49:225-233

47. Boogers MJ, Borleffs CJW, Henneman MM, Van Bommel RJ, Van Ramshorst J, Boersma E, Dibbets-Schneider P, Stokkel MP, van der Wall EE, Schalij MJ, Bax JJ (2010) Cardiac sympathetic denervation assessed with 123-I MIBG imaging predicts ventricular arrhythmias in implantable cardioverter-defibrillator patients. J Am Coll Cardiol 55:2769-2777

48. Zipes DP (1991) Sympathetic stimulation and arrhythmias. N Engl J Med 325:656-657
49. Desantiago J, Ai X, Islam M, Acuna G, Ziolo MT, Bers DM, Pogwizd SM (2008) Arrhythmogenic effects of beta2-adrenergic stimulation in the failing heart are attributable to enhanced sarcoplasmic reticulum Ca load. Circ Res 102:1389-1397

50. Ungerer M, Hartmann F, Karoglan M, Chlistalla A, Ziegler S, Richardt G, Overbeck M, Meisner H, Schomig A, Schwaiger M (1998) Regional in vivo and in vitro characterization of autonomic innervation in cardiomyopathic human heart. Circulation 97:174-180

51. Hartmann F, Ziegler S, Nekolla S, Hadamitzky M, Seyfarth M, Richardt G, Schwaiger M (1999) Regional patterns of myocardial sympathetic denervation in dilated cardiomyopathy: an analysis using carbon-11 hydroxyephedrine and positron emission tomography. Heart 81:262-270

52. Vesalainen RK, Pietila M, Tahvanainen KU, Jartti T, Teras M, Nagren K, Lehikoinen P, Huupponen R, Ukkonen H, Saraste M, Knuuti J, Voipio-Pulkki LM (1999) Cardiac positron emission tomography imaging with [11C]hydroxyephedrine, a specific tracer for sympathetic nerve endings, and its functional correlates in congestive heart failure. Am J Cardiol 84:568-574

53. Pietila M, Malminiemi K, Ukkonen H, Saraste M, Nagren K, Lehikoinen P, Voipio-Pulkki LM (2001) Reduced myocardial carbon-11 hydroxyephedrine retention is associated with poor prognosis in chronic heart failure. Eur J Nucl Med 28:373-376

54. Bengel FM, Ueberfuhr P, Schiepel N, Nekolla SG, Reichart B, Schwaiger M (2001) Myocardial efficiency and sympathetic reinnervation after orthotopic heart transplantation: a noninvasive study with positron emission tomography. Circulation 103:18811886

55. Bengel FM, Permanetter B, Ungerer M, Nekolla SG, Schwaiger M (2002) Alterations of the sympathetic nervous system and metabolic performance of the cardiomyopathic heart. Eur J Nucl Med Mol Imag 29:198-202

56. Bengel FM, Ueberfuhr P, Hesse T, Schiepel N, Ziegler SI, Scholz S, Nekolla SG, Reichart B, Schwaiger M (2002) Clinical determinants of ventricular sympathetic reinnervation after orthotopic heart transplantation. Circulation 106:831-835

57. Di Carli MF, Tobes MC, Mangner T, Levine AB, Muzik O, Chakroborty P, Levine TB (1997) Effects of cardiac sympathetic innervation on coronary blood flow. N Engl J Med 336:1208-1215

58. Sasano T, Abraham MR, Chang KC, Ashikaga H, Mills KJ, Holt DP, Hilton J, Nekolla SG, Dong J, Lardo AC, Halperin H, Dannals RF, Marban E, Bengel FM (2008) Abnormal sympathetic innervation of viable myocardium and the substrate of ventricular tachycardia after myocardial infarction. J Am Coll Cardiol 51:2266-2275

59. Mann DL, Spinale FG (1998) Activation of matrix metalloproteinases in the failing human heart: breaking the tie that binds. Circulation 98:1699-1702

60. Mukherjee R, Brinsa TA, Dowdy KB, Scott AA, Baskin JM, Deschamps AM, Lowry AS, Escobar GP, Lucas DG, Yarbrough WM, Zile MR, Spinale FG (2003) Myocardial infarct expansion and matrix metalloproteinase inhibition. Circulation 107:618-625

61. Su H, Spinale FG, Dobrucki LW, Song J, Hua J, Sweterlitsch S, Dione DP, Cavaliere P, Chow C, Bourke BN, Hu XY, Azure M, Yalamanchili P, Liu R, Cheesman EH, Robinson S, Edwards DS, Sinusas AJ (2005) Noninvasive targeted imaging of matrix metalloproteinase activation in a murine model of postinfarction remodeling. Circulation 112:3157-3167

62. Peterson LR, Gropler RJ (2010) Radionuclide imaging of myocardial metabolism. Circ Cardiovasc Imag 3:211-222

63. Lautamaki R, Tipre D, Bengel FM (2007) Cardiac sympathetic neuronal imaging using PET. Eur J Nucl Med Mol Imag 34:S74S85

64. Verjans JW, Lovhaug D, Narula N, Petrov AD, Indrevoll B, Bjurgert E, Krasieva TB, Petersen LB, Kindberg GM, Solbakken 
M, Cuthbertson A, Vannan MA, Reutelingsperger CP, Tromberg BJ, Hofstra L, Narula J (2008) Noninvasive imaging of angiotensin receptors after myocardial infarction. JACC Cardiovasc Imag 1:354-362

65. Meoli DF, Sadeghi MM, Krassilnikova S, Bourke BN, Giordano FJ, Dione DP, Su H, Edwards DS, Liu S, Harris TD, Madri JA, Zaret BL, Sinusas AJ (2004) Noninvasive imaging of myocardial angiogenesis following experimental myocardial infarction. J Clin Invest 113:1684-1691

66. Higuchi T, Bengel FM, Seidl S, Watzlowik P, Kessler H, Hegenloh R, Reder S, Nekolla SG, Wester HJ, Schwaiger M (2008) Assessment of alphavbeta3 integrin expression after myocardial infarction by positron emission tomography. Cardiovasc Res 78:395-403

67. Rodriguez-Porcel M, Cai W, Gheysens O, Willmann JK, Chen K, Wang H, Chen IY, He L, Wu JC, Li ZB, Mohamedali KA, Kim S, Rosenblum MG, Chen X, Gambhir SS (2008) Imaging of VEGF receptor in a rat myocardial infarction model using PET. J Nucl Med 49:667-673

68. Kramer CM, Sinusas AJ, Sosnovik DE, French BA, Bengel FM (2010) Multimodality imaging of myocardial injury and remodeling. J Nucl Med 51:107S-121S

69. Kraitchman DL, Heldman AW, Atalar E, Amado LC, Martin BJ, Pittenger MF, Hare JM, Bulte JW (2003) In vivo magnetic resonance imaging of mesenchymal stem cells in myocardial infarction. Circulation 107:2290-2293

70. Brenner W, Aicher A, Eckey T, Massoudi S, Zuhayra M, Koehl U, Heeschen C, Kampen WU, Zeiher AM, Dimmeler S, Henze E (2004) 111In-labeled CD34+ hematopoietic progenitor cells in a rat myocardial infarction model. J Nucl Med 45:512-518
71. Hofmann M, Wollert KC, Meyer GP, Menke A, Arseniev L, Hertenstein B, Ganser A, Knapp WH, Drexler H (2005) Monitoring of bone marrow cell homing into the infarcted human myocardium. Circulation 111:2198-2202

72. Bengel FM, Anton M, Richter T, Simoes MV, Haubner R, Henke J, Erhardt W, Reder S, Lehner T, Brandau W, Boekstegers P, Nekolla SG, Gansbacher B, Schwaiger M (2003) Noninvasive imaging of transgene expression by use of positron emission tomography in a pig model of myocardial gene transfer. Circulation 108:2127-2133

73. Higuchi T, Anton M, Dumler K, Seidl S, Pelisek J, Saraste A, Welling A, Hofmann F, Oostendorp RA, Gansbacher B, Nekolla SG, Bengel FM, Botnar RM, Schwaiger M (2009) Combined reporter gene PET and iron oxide MRI for monitoring survival and localization of transplanted cells in the rat heart. J Nucl Med 50:1088-1094

74. Terrovitis J, Kwok KF, Lautamaki R, Engles JM, Barth AS, Kizana E, Miake J, Leppo MK, Fox J, Seidel J, Pomper M, Wahl RL, Tsui B, Bengel F, Marban E, Abraham MR (2008) Ectopic expression of the sodium-iodide symporter enables imaging of transplanted cardiac stem cells in vivo by single-photon emission computed tomography or positron emission tomography. J Am Coll Cardiol 52:1652-1660

75. Terrovitis J, Lautamaki R, Bonios M, Fox J, Engles JM, Yu J, Leppo MK, Pomper MG, Wahl RL, Seidel J, Tsui BM, Bengel FM, Abraham MR, Marban E (2009) Noninvasive quantification and optimization of acute cell retention by in vivo positron emission tomography after intramyocardial cardiac-derived stem cell delivery. J Am Coll Cardiol 54:1619-1626 